\title{
Prone positioning in non-intubated patients with COVID-19
}

\author{
Aslıhan GÜRÜN \\ $\operatorname{KAYA}^{\mathbf{1}}(\mathrm{ID})$ \\ Miraç ÖZ ${ }^{1}$ (ID) \\ Serhat $\operatorname{EROL}^{1}($ ID) \\ Fatma ÇiFTÇi ${ }^{1}$ (ID) \\ Aydın ÇiLEDAĞ ${ }^{\mathbf{1}}$ (ID) \\ Akın KAYA ${ }^{\mathbf{1}}$ (ID)
}

\author{
${ }^{1}$ Department of Chest Diseases, Faculty of Medicine, Ankara University, \\ Ankara, Turkey \\ 1 Ankara Üniversitesi Tıp Fakültesi, Göğ̈̈s Hastalıkları Anabilim Dalı, \\ Ankara, Türkiye
}

\begin{abstract}
Cite this article as: Gürün Kaya A, Öz M, Erol S, Çiftçi F, Çiledağ A, Kaya A. Prone positioning in non-intubated patients with COVID-19. Tuberk Toraks 2020;68(3):331 336.
\end{abstract}

Yazışma Adresi (Address for Correspondence)

\section{Dr. Aslıhan GÜRÜN KAYA}

Ankara Üniversitesi Tıp Fakültesi,

Göğüs Hastalıkları Anabilim Dalı,

ANKARA - TÜRKIYE

e-mail: agkaya@ankara.edu.tr

CCopyright 2020 by Tuberculosis and Thorax.

Available on-line at www.tuberktoraks.org.com

\begin{abstract}
Prone positioning in non-intubated patients with COVID-19

Prone positioning is a well-known supportive maneuver to improve oxygenation for patients with moderate to severe acute respiratory distress syndrome (ARDS). Although this technique is usually performed to sedated patients on invasive mechanical ventilation, it has been used in non-intubated patients frequently during the coronavirus diseases-2019 (COVID-19) pandemic. Favorable outcomes have been reported mainly in combining the prone positioning with high flow nasal cannula (HFNC) or non-invasive ventilation (NIV). Due to limited data, a standard approach for the awake prone positioning has not yet been defined. In this manuscript, we reviewed the literature data about prone positioning in non-intubated patients with COVID-19. According to available literature data, we concluded that prone positioning in non-intubated COVID-19 patients may improve oxygenation and prevent the need for invasive mechanical ventilation. But the efficacy is still controversial in the early stage of the disease due to pulmonary mechanics. Further studies are needed to the defined optimal approach of awake prone positioning in COVID-19 patients with hypoxemic respiratory failure.
\end{abstract}

Key words: Prone positioning; COVID-19; hypoxemic respiratory failure

ÖZ

\section{Entübe olmayan COVID-19 hastalarında pron pozisyon}

Pron pozisyon, orta ila şiddetli akut solunum sıkıntısı sendromu (ARDS) olan hastalarda oksijenazyonu iyileştirmek için destekleyici bir manevradır. Bu teknik genellikle invaziv mekanik ventilasyon desteği altındaki sedatize hastalarda uygulanmasına rağmen, Coronavirüs-2019 (COVID-19) pandemisinde sıklıkla entübe olmayan hastalarda da uygulanmıştır. Özellikle yüksek akışlı nazal kanül (HFNC) veya non-invaziv ventilasyon (NIV) tedavileri ile birlikte kullanıldığı hastalarda olumlu sonuçlar bildirilmiştir. Ancak konu ile ilgili sınırlı veri olması nedeniyle, uyanık pron pozisyon uygulaması için standart bir yaklaşım henüz tanımlanmamıştır. Bu yazıda, COVID-19 tanılı entübe olmayan hastalarda pron pozisyon uygulamaları hakkındaki literatür verileri gözden geçirilmiştir. Mevcut literatür verilerine göre, entübe edilmemiş COVID-19 
hastalarında pron pozisyon uygulamalarının, hastaların oksijenasyonunu iyileştirebileceği ve invaziv mekanik ventilasyon ihtiyacını azaltabileceği düşünülmektedir. Ancak pulmoner sistem mekanikleri üzerine etkileri nedeniyle hastalığın erken evresinde etkinlik hala tartışmalıdır. Hipoksemik solunum yetmezliği olan COVID-19 hastalarında pron pozisyon için standart yaklaşımların belirlenebilmesi için daha fazla çalışmaya ihtiyaç bulunmaktadır.

Anahtar kelimeler: Pron pozisyon; COVID-19; hipoksemik solunum yetmezliği

Prone positioning is a well-known supportive maneuver to improve oxygenation for patients with moderate to severe acute respiratory distress syndrome (ARDS). This technique is usually performed to sedated patients on invasive mechanical ventilation (1).

Although the possible positive effects of prone positioning in non-intubated patients have been shown, it has been used more frequently during the coronavirus diseases-2019 (COVID-19) pandemic. Furthermore, favorable outcomes have been reported mainly in combining the prone positioning with high flow nasal cannula (HFNC) (Figure 1) or non-invasive ventilation (NIV) $(2,3)$. Coppo and colleagues conducted a prospective study to evaluate the effects of prone positioning in non-intubated patients with acute respiratory failure due to COVID-19. Fifty-six patients were included to this study, and it was

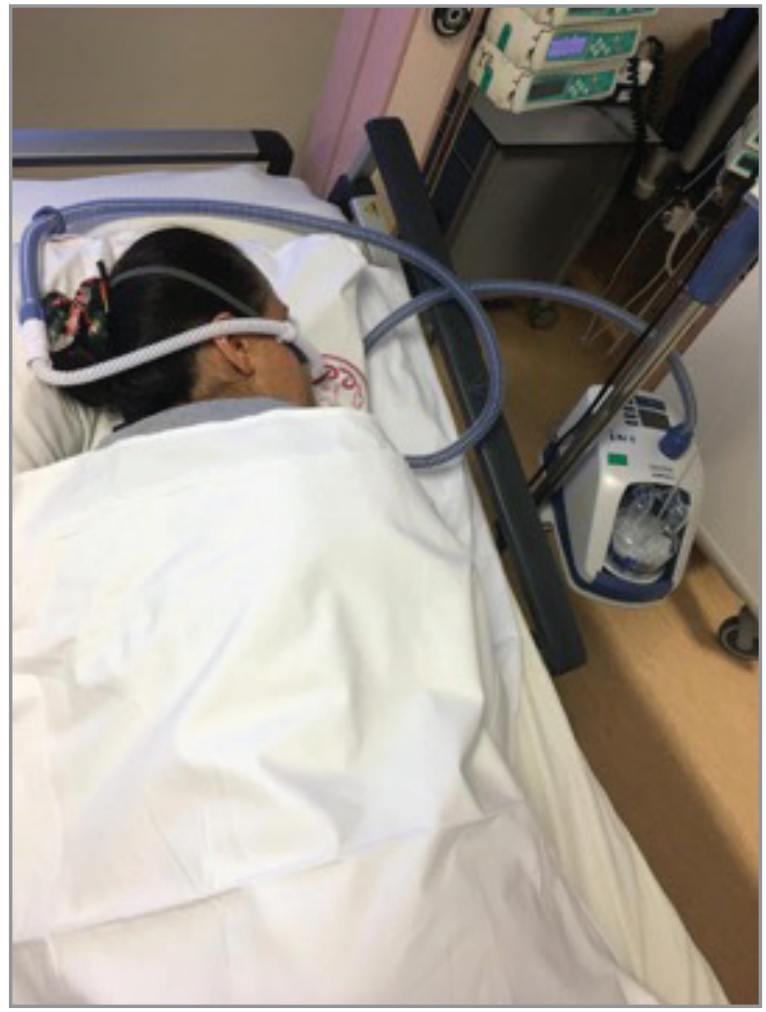

Figure 1. Combined HFNC treatment and prone positioning in a patient with COVID-19 pneumonia. reported that oxygenation significantly improved from supine to prone positioning (partial arterial oxygen pressure/fraction of inspiratory oxygen $-\mathrm{PaO}_{2} /$ $\mathrm{FiO}_{2}$ ratio $180.5 \pm 76.6$ vs $\left.285 \pm 112.9 \mathrm{p}<0.0001\right)$. But only $50 \%$ of study patients could maintain this improved oxygenation after resupination, and this improvement was not significant compared with before prone positioning (4). In another study by Caputo et al. it was shown that oxygenation significantly improved after 5 minutes of prone positioning in patients suspected COVID-19 with hypoxia on arrival to the emergency department. Thirteen of these fifty patients $(24 \%)$ required endotracheal intubation within 24 hours. Notably, most of these patients required endotracheal intubation consisted of patients whose oxygen saturation measured by pulse oximeter $\left(\mathrm{SpO}_{2}\right)$ value could not be achieved $95 \%$ with the prone position in the $5^{\text {th }}$ minute (5). In another study, Thompson and colleagues reported that 25 of 29 patients in their study had an awake prone position at least one hour and after one-hour $\mathrm{SpO}_{2}$ level increased compared with the baseline (median [SE], 7\% [1.2\%]; 95\% Cl, $4.6 \%-9.4 \%$ ) (6). Elharrar et al. reported that among the 24 study patients, four patients did not tolerate prone position more than one hour, five of them tolerated 1 to 3 hours, and 15 of them tolerated prone position more than three hours. Although oxygenation of $25 \%$ of study patients improved during prone position, it did not sustain in half of those after resupination (7). These studies are summarized in Table 1.

In addition to these studies, several cases and case series were reported a potential improvement in oxygenation with prone positioning in non-intubated patients with COVID-19 infection (3,8-12).

\section{The Main Physiological Effect of Prone Positioning in Hypoxemic Respiratory Patients}

The prone positioning improves oxygenation with different mechanisms, including decreasing the ventral-dorsal transpulmonary pressure difference, reducing dorsal lung compression, and improving lung perfusion, increasing functional residual capacity 


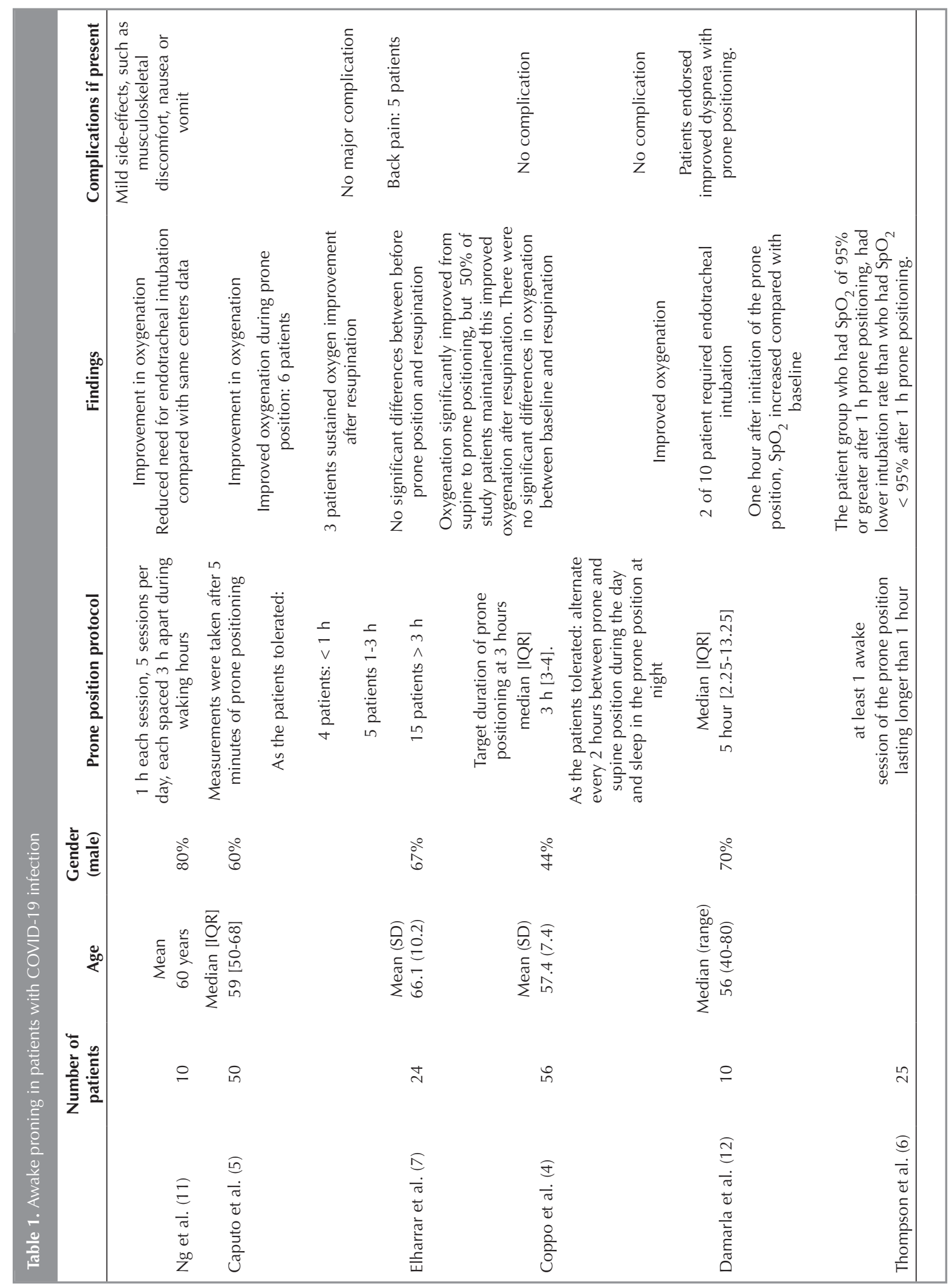


(FRC). Moreover, the distribution of extravascular lung water and mobilisation of secretions may have other beneficial effects of prone positioning, that provide improving ventilation.

The main effect of prone positioning is reducing the differences between ventral and dorsal pleural pressure. On supine position, dorsal pleural pressure is higher than ventral pleural pressure. Besides that, alveoli medial posterior and posterio-caudal lung parenchyma collapse due to both heart and diaphragm compression. After placing prone position, the heart becomes dependent, and diaphragm displaces caudally. These changes lead to a decrease in lung compression. These collapsed alveoli may be recruited with prone positioning. Although less than ventilation, the prone position also has effects on perfusion. Improved perfusion of the dependent lung regions with prone positioning is thought to be partially responsible for the improved oxygenation. Prone positioning may also prevent atelectasis and improve recruitment of pulmonary parenchyma by improving secretion management (3,13-15).

Gattinoni et al. hypothesized that lung compliance is high, and recruitability is minimal in the early phases of COVID-19 pneumonitis. The predominant cause of hypoxemia in this phase is impaired pulmonary perfusion. In these early phases, prone positioning could temporarily improve ventilation/perfusion mismatch. With disease progression, COVID-19 pneumonitis starts behaving like typical ARDS with low lung compliance and high recruitability (16). For this reason, it is thought to sustained efficacy of the prone positioning could be seen in late phases of COVID-19 (13).

\section{Applications of Prone Positioning}

Due to limited data, a standard approach for the awake prone positioning has not yet been defined. While most of the cases were reported with the prone and resupine position, some experts recommended positioning protocols include the prone position, followed by left lateral decubitus, right lateral decubitus, and upright sitting position $(5,17)$.

\section{Selection of Appropriate Patient}

Although there is no consensus on the selection/ exclusion of the appropriate patient yet, the inclusion characteristics of the patients for awake prone positioning in the reports are similar. Awake prone positioning is not suitable for patients with severe respiratory failure $\left(\mathrm{PaO}_{2} / \mathrm{FiO}_{2}<100\right)$ due to the risk of delaying intubation and subsequent treatment failure. Also, recent abdominal surgery increased intraabdominal pressure, facial injuries and unstable fractures are defined as a contraindication for prone positioning $(10,14)$.

Huang et al. declared their selection criteria for prone positioning; 1) $\mathrm{SpO}_{2}<92 \%$ under $6 \mathrm{lt} / \mathrm{min}$ nasal oxygen or $50 \% \mathrm{FiO} 2$ venturi mask or $\mathrm{PaO}_{2} / \mathrm{FiO}_{2}<200$, 2 ) radiological opacities bilaterally, 3 ) respiratory rate $<30 /$ min, 4) not using accessory muscle for breathing (18). Bower et al., reported that they applied awake prone positioning to patients with mild to moderate ARDS, but not requiring immediate intubation, increased respiratory rate (>40/min), accessory respiratory muscle use, tachycardia $>100$, decreased systolic blood pressure $(<100 \mathrm{mmHg})$ and unstable spine/body habitus (19). In another case series by Paul et al. selection criteria for awake prone positioning were described as; acute hypoxemia related COVID-19, oxygen requirements ( $>2 \mathrm{lt} / \mathrm{min}$ ) to maintain $\mathrm{SpO}_{2}$ 92\%, able to communicate, follow instructions and able to prone/supine themselves with minimal assistance. Besides that, in this study, hemodynamic instability, facial/neck trauma, spinal instability, significant hemoptysis and pregnancy were determined as exclusion factors for prone positioning (3). Damarla et al. reported nine adult COVID-19 patients receiving prone positioning who have rapidly increasing oxygen requirements necessitating intensive care admission, but not requiring invasive mechanical ventilation yet. The authors also indicated that patients requiring urgent mechanical intubation were not eligible for proning (12). Thompson et al. performed a study with 88 patients to evaluate the efficacy of prone positioning in non-intubated COVID-19 patients. Inclusion criteria for prone positioning were defined as increased respiratory rate (> 30 breaths/ $\mathrm{min}$ ) and $\mathrm{SpO}_{2}$ of $93 \%$ or less while receiving supplemental oxygen $6 \mathrm{~L} / \mathrm{min}$ via nasal cannula and $15 \mathrm{~L} / \mathrm{min}$ via nonrebreather face mask. The patients who had altered mental status, extreme respiratory distress requiring invasive ventilation were excluded (6). According to this evidence, mild to moderate hypoxemic patients who can able to cooperate with medical staff may suitable for awake prone positioning. Altered mental status, hemodynamic instability, face trauma, clinical situations related increases intraabdominal pressure, spinal instabilities, or fractures can be determined as a contraindication. 


\section{Duration of Prone Positioning}

The optimal duration is suggested about 12-16 hours per day for patients in invasive mechanical ventilation with moderate to severe ARDS. A meta-analysis by Munshi et al. revealed that prone position could lead to decrease in the rate of mortality in patients with severe ARDS when applied to patients for least 12 hours a day (20). Unlike sedated ARDS patients in invasive mechanical ventilation, the duration of the prone position in non-intubated patients is dependent on tolerance and comfort of patients. The duration was declared varies 30 minutes to 8 hours in previous reports. Also, each session was applied 2-3 times or more during the day in those reports. In the study by Coppo et al. 47 of the total 56 patients were feasible for prone positioning at least 3 hours (median 3 hours [IQR 3-4]). Oxygenation significantly improved from supine to prone positioning. But after resupination, improved oxygenation level could be maintained in only 23 patients (4). $\mathrm{Ng}$ et al. observed that one of ten patient who was undergone prone positioning required invasive mechanical ventilation. They applied prone positioning for 1 hour each session, five sessions per day, each spaced 3 hours apart during waking hours. When they compared with their center data, prone positioning was associated with lower intubation rate in COVID-19 patients who required supplemental oxygen ( $10 \%$ vs $60 \%$ ) (11). Xu et al. reported 10 COVID-19 patients who were received awake prone positioning with HFNC therapy. The authors stated mean $\mathrm{PaO}_{2} / \mathrm{FiO}_{2}$ improved after a prone position, and none of the cases required invasive mechanical ventilation. The target time of prone positioning is more than 16 hours per day in these cases (21). As can be seen in recent data, there is no consensus yet on the optimal duration in the awake prone position. Also, available data suggest that the longer duration of the prone position may associate with treatment success. However, if it is determined that the patient does not benefit or deteriorated under the prone position, the prone position should not be prolonged, and other supportive treatment options should be considered.

\section{Follow-Up of the Patients During Prone Positioning}

The tolerance and monitoring of patients during prone positioning are essential factors for treatment success. Monitoring parameters have not well-identified for treatment success. In the report by Huang et al. where prone position and HFNC combination therapy were evaluated, the authors suggested to terminate the prone position if the patient cannot tolerate the prone position, in the presence of clinical deterioration, and the ROX index is $<4.88$ despite optimal HFNC therapy (18). ROX index is defined as the ratio of $\mathrm{SpO}_{2} / \mathrm{FiO}_{2}$ to respiratory rate to predict of clinical outcomes of patients who received HFNC treatment. Still, it has not been validated in patients with COVID-19 $(11,22)$. Jiang et al. recommended some follow-up requirements as the following; patients should be made as comfortable as possible with placing a pillow and using the toilet beforehand. A call bell should be placed at the bedside that patients can reach. The patients should be supported via enough oxygen via conventional oxygen, HFNC or NIV as well as being on a continuous respiratory monitor. The patients should be provided with an instructional handout which includes a visual aid explaining the position. Patients are re-assessed by care providers or nursing every 30 minutes for the first hour and every hour for the following two hours (17).

\section{The Complications of Prone Positioning}

There are potential complications of prone positioning. Unable to tolerate prone position due to body discomfort may lead to anxiety in these patients and they may require light sedation. Pressure ulcers are another common complication of prone positioning. Pillows or blankets could be placed under the risk for pressure ulceration such as the hips/pelvis (17). Gastric distention and gastroesophageal reflux, vomiting may be seen in these patients. Accidentally disconnection of oxygen supplement system may present during prone positioning. To detect any clinical deterioration, the patients should be monitored closely during prone positioning (3).

\section{Conclusion}

In conclusion, prone positioning in non-intubated COVID-19 patients may improve oxygenation and prevent the need for invasive mechanical ventilation. The prone position can be applied to patients receiving HFNC and NIV therapy, as well as patients receiving conventional oxygen support. But the efficacy is still controversial in the early stage of the disease due to pulmonary mechanics. Further studies are needed to the defined optimal approach of awake prone positioning in COVID-19 patients with hypoxemic respiratory failure. 


\section{REFERENCES}

1. Gattinoni L, Busana M, Giosa L, Macri MM, Quintel M. Prone positioning in acute respiratory distress syndrome. Semin Respir Crit Care Med 2019; 40(1): 94-100.

2. Ding L, Wang L, Ma W, He H. Efficacy and safety of early prone positioning combined with HFNC or NIV in moderate to severe ARDS: a multi-center prospective cohort study. Crit Care 2020; 24(1): 28.

3. Paul V, Patel S, Royse M, Odish M, Malhotra A, Koenig S. Proning in non-intubated (PINI) in times of COVID-19: Case series and a review. I Intensive Care Med 2020; 35(8): 818-24.

4. Coppo A, Giacomo, Winterton D, Di Pierro M, Soria A, Faverio $P$, et al. Feasibility and physiological effects of prone positioning in non-intubated patients with acute respiratory failure due to COVID-19 (PRON-COVID): a prospective cohort study. Lancet Resp Med 2020; 8(8): 765-74.

5. Caputo ND, Strayer RJ, Levitan R. Early self-proning in awake, non-intubated patients in the emergency department: A single ED's experience during the COVID-19 pandemic. Acad Emerg Med 2020; 27(5): 375-8.

6. Thompson AE, Ranard BL, Wei Y, Jelic S. Prone positioning in awake, non-intubated patients with COVID-19 hypoxemic respiratory failure. JAMA Intern Med 2020; e203030.

7. Elharrar X, Trigui $Y$, Dols AM, Touchon F, Martinez S, Prud'homme $E$, et al. Use of prone positioning in non-intubated patients with COVID-19 and hypoxemic acute respiratory failure. Jama-J Am Med Assoc 2020; 323(22). 2336-8.

8. Sztajnbok J, Maselli-Schoueri JH, Brasil LMCD, de Sousa LF, Cordeiro CM, Borges LMS, et al. Prone positioning to improve oxygenation and relieve respiratory symptoms in awake, spontaneously breathing non-intubated patients with COVID-19 pneumonia. Respiratory Medicine Case Reports 2020; 30

9. $X u Q H$, Wang T, Qin XM, Jie $Y L$, Zha $L, L u W H$. Early awake prone position combined with high-flow nasal oxygen therapy in severe COVID-19: a case series. Critical Care 2020; 24(1).

10. Cohen D, Wasserstrum Y, Segev A, Avaky C, Negru L, Turpashvili $N$, et al. Beneficial effect of awake prone position in hypoxaemic patients with COVID-19: case reports and literature review. Intern Med / 2020; 10.1111/ imj. 14926 .
11. Ng Z, Tay WC, Ho CHB. Awake prone positioning for non-intubated oxygen dependent COVID-19 pneumonia patients. Eur Respir J 2020; 56(1)

12. Damarla $M$, Zaeh $S$, Niedermeyer $S$, Merck S, NiranjanAzadi A, Broderick B, et al. Prone positioning of non-intubated patients with COVID-19. Am J Resp Crit Care 2020; 202(4): 604-6

13. Koeckerling D, Barker J, Mudalige NL, Oyefeso O, Pan D, Pareek M, et al. Awake prone positioning in COVID-19. Thorax 2020; 75(10): 833-4.

14. Valter C, Christensen AM, Tollund C, Schonemann NK. Response to the prone position in spontaneously breathing patients with hypoxemic respiratory failure. Acta Anaesth Scand 2003; 47(4): 416-8.

15. Sud S, Sud M, Friedrich JO, Adhikari NKJ. Effect of prone positioning in patients with acute respiratory distress syndrome and high Simplified Acute Physiology Score II. Crit Care Med 2008; 36(9): 2711-2.

16. Gattinoni L, Chiumello D, Caironi P, Busana M, Romitti F, Brazzi L, et al. COVID-19 pneumonia: different respiratory treatments for different phenotypes? Intensive Care Med 2020; 46(6): 1099-102.

17. Jiang LG, LeBaron J, Bodnar D, Caputo ND, Chang BP, Chiricolo $G$, et al. Conscious proning: an introduction of a proning protocol for non-intubated, awake, hypoxic emergency department COVID-19 patients. Acad Emerg Med 2020; 27(7): 566-9.

18. Huang CF, Tay CK, Zhuang YF, Liu JX, Sewa DW. Rationale and significance of patient selection in awake prone positioning for COVID-19 pneumonia. Eur Respir J 2020; 56(3).

19. Bower G, He HY. Protocol for awake prone positioning in COVID-19 patients: to do it earlier, easier, and longer. Critical Care 2020; 24(1).

20. Munshi L, Del Sorbo L, Adhikari NKJ, Hodgson CL, Wunsch $H$, Meade MO, et al. Prone position for acute respiratory distress syndrome. A systematic review and meta-analysis. Ann Am Thorac Soc 2017; 14(Supp/4): S280-S8.

21. Xu Q, Wang T, Qin X, Jie Y, Zha L, Lu W. Early awake prone position combined with high-flow nasal oxygen therapy in severe COVID-19: a case series. Crit Care 2020; 24(1): 250.

22. Gurun Kaya A, Oz M, Erol S, Ciftci F, Ciledag A, Kaya A. High flow nasal cannula in COVID-19: a literature review. Tuberk Toraks 2020; 68(2): 168-74. 